\title{
DOSSIÊ CONSUMO E SOCIABILIDADES
}

ntre os dias 4 e 5 de abril de 2018, o Grupo de Pesquisa Consumo e Sociabilidades (ESPM Rio/CNPq), formado por pesquisadoras da ESPM, da UERJ e da UFRGS, promoveu, no auditório da ESPM Rio, a I Jornada de Pesquisa sobre Consumo e Sociabilidades. Em linhas gerais, o evento teve como proposta central a promoção do debate sobre o lugar do consumo na construção de sociabilidades contemporâneas no contexto urbano, possibilitando a reflexão sobre as teorias acerca das sociedades e das culturas a fim de compreender o fenômeno do consumo em seus sentidos, suas percepções, suas práticas, seus rituais, suas transformações e seus impactos na vida social das cidades. Naqueles dois dias foram apresentados trabalhos de pesquisadores de diferentes instituições que deram uma mostra da amplitude de temas tratados dentro do campo dos estudos do consumo. Agrupados em quatro sessões - Consumo e Alimentação; Moda, Juventude e Sustentabilidade; Consumo e Gênero; e Consumo, Sociedade e Mercados, os participantes que tiveram seus trabalhos acolhidos na Jornada tiveram a oportunidade de compartilhar conhecimentos, trocar ideias e debater sobre as possibilidades de desenvolvimento de suas atuais e de futuras pesquisa.

Este dossiê reúne alguns dos trabalhos apresentados na Jornada. Com aportes conceituais e percursos metodológicos diversos, esse conjunto de textos reafirmam a perspectiva de que o consumo tem se revelado um aspecto dos mais relevantes na compreensão da sociedade contemporânea, seja pelo reconhecimento do surgimento de novas e renovadas formas de sociabilidade que reconfiguram hábitos, práticas, narrativas e sentidos de consumo, seja em função do advento de novos e variados espaços, mercadorias e comportamentos de consumo que impactam nas relações sociais contemporâneas.

Abrindo esta edição, o artigo Alimento e comida: reflexões sobre história do alimento, consumo e significados, de autoria de Flavia Cupolillo Yamagata e João Felipe Rammelt Sauerbronn, um ensaio teórico que destaca aspectos da história social da alimentação e aos conceitos de alimento e comida, traz reflexões importantes sobre novas perspectivas que têm sido incorporadas às pesquisas sobre práticas de consumo de comida. O ensaio explora essa discussão como forma de construir uma compreensão mais profunda a respeito dos aspectos simbólicos e culturais do consumo alimentar.

Na sequência, Cristiane Silva do Nascimento Pereira, Denise Franca Barros e Marcus Wilcox Hemais, autores de A escola como ambiente obesogênico: as influências sobre a alimentação infantil, a partir da vulnerabilidade do consumidor, apresentam as principais influências que contribuem para o consumo infantil de alimentos obesogênicos nas escolas. A partir de dezessete entrevistas em profundidade realizadas com diferentes agentes presentes nesse mercado, na cidade do Rio de Janeiro, é possível compreender que a vulnerabilidade infantil é crescente no Brasil, em grande parte devido à existência de uma estrutura mercadológica impulsionada pelo sistema de marketing desenvolvido por grandes empresas.

O consumo de comida via aplicativos de delivery no ambiente laboral: um caminho para precarização do trabalho?, de Flora Thamiris Rodrigues Bittencourt, mostra que atualmente muitos trabalhadores, com o intuito de poupar tempo ou devido ao re- 
duzido horário de almoço, priorizam comer sem sair de seus locais de trabalho, passaram a solicitar suas refeições via aplicativos de delivery. Partindo dessa constatação, a autora traz uma relevante discussão sobre como o consumo de comida por meio da proliferação de aplicativos de delivery no ambiente laboral pode propiciar a precarização do trabalho.

No quarto artigo, intitulado A Rocinha e seus espaços de consumo: uma observação etnográfica, Daniela Jacques da Cruz apresenta parte dos resultados de uma pesquisa realizada no âmbito do Mestrado Profissional em Gestão da Economia Criativa da ESPM Rio. A partir de uma etnografia conduzida durante dezessete meses na favela da Rocinha, localizada na zona sul da cidade do Rio de Janeiro, a autora descreve e analisa os principais espaços de consumo presentes naquela comunidade. Com base em um marco teórico fundamentado na antropologia do consumo, o artigo contextualiza a Rocinha do ponto de vista cultural, social e econômico, e analisa a diversidade de espaços de consumo, de produtos e de serviços presentes naquele que é popularmente conhecida como "a maior favela do Brasil".

O artigo Esculpindo Barbies por meio de suplementos alimentares: corpo, gênero e consumo por uma ótica Queer, de Renan Gomes de Moura, nos revela como o consumo de suplementos alimentares por parte de determinado grupo identitário gay, conhecido como Barbies, colabora com a construção da identidade desse grupo através do corpo. A partir da seleção e da análise de trechos de matérias publicadas no site Super Pride no ano de 2016, o autor verifica a existência de diversas estratégias de construção de identidade e explica como esses indivíduos constroem seus corpos através do "culto ao corpo" que tem por objetivo o crescimento e a definição de músculos.

O artigo Moda sustentável: um estudo qualitativo com jovens empreendedores desse setor, de Leonardo Jacques Gammal Zeitune, analisa como o mercado da moda, setor da Economia Criativa, funciona a partir da adoção de práticas sustentáveis sob a ótica de jovens empreendedores. Para isso, foi realizada uma pesquisa qualitativa por meio de entrevistas via redes sociais e Skype, acompanhada de um roteiro de perguntas pré-estruturado. Os achados da pesquisa confirmam que a tendência deste setor é a adoção de práticas sustentáveis em todas as faces do seu setor produtivo, visando à minimização do impacto de sua produção ao meio ambiente, porém ao mesmo tempo, assegurando a qualidade de seus produtos.

Fechando esta edição, Luíza Marques Fázzio e Beatriz Russo Rodrigues nos apresentam o artigo Investigando a monocultura econômica para práticas publicitárias conscientes. Nele, partindo da perspectiva da monocultura econômica, as autoras investigam os problemas socioambientais resultantes da cadeia de produção linear. Identificam o consumo como uma etapa fundamental e o profissional da publicidade e propaganda como elo importante para a manutenção dessa monocultura. Nesse sentido, apontam para os movimentos que buscam quebrar a monocultura vigente e para a necessidade de buscar caminhos mais circulares, conscientes e responsáveis para a atuação dos profissionais da publicidade e propaganda.

Desejamos a todos uma proveitosa e prazerosa leitura.

Sílvia Borges Corrêa e Veranise Jacubowski Dubeux 